\title{
Delegadas de polícia: profissionalismo e gênero
}

\author{
Maria Natália Barboza da Silveira \\ Doutoranda em Sociologia (Universidade Federal de São Carlos) \\ naty_silveirag@hotmail.com
}

Resumo O presente trabalho estudou a presença feminina na carreira jurídica de delegado de polícia, que é uma profissão tradicionalmente masculina. A Delegacia de Defesa da Mulher (DDM) foi avaliada para que se pudesse verificar se a reserva de mercado instaurada por esse órgão contribuiu para um processo de subalternização dessas profissionais perante os pares. O trabalho constatou que, se, por um lado, a inauguração das DDMs canalizou mais as mulheres para trabalharem nesses órgãos, por outro, contribuiu para um aprisionamento da trajetória profissional delas. Isso porque, para muitas delegadas, o trabalho em uma DDM é considerado um atravancamento para a carreira. A pesquisa foi realizada na cidade de São Paulo, onde foram estudados os distritos policiais e as delegacias de defesa da mulher. O estudo foi realizado de 2007 até 2009.

Palavras-chave: delegadas de polícia, profissão, gênero, Delegacias de Defesa da Mulher, Distritos Policiais

\section{Introdução}

A S PROFissões, EM ESPECIAL DA ÁREA do Direito, se organizaram em um contexto histórico no qual a esfera profissional era direcionada aos homens. A criação e fundação dos cursos jurídicos no Brasil ocorrem na primeira metade do século XIX. Até então, estes espaços públicos eram reservados aos homens. Segundo Barbalho (2008), os trabalhos acadêmicos sobre a origem e organização das profissões jurídicas não registram a presença de mulher. Para a autora, as consequências de uma ordem criadora, na qual a preponderância hegemônica é branca, masculina e heterossexual, compondo assim um script sexuado, reforçam os traços de desigualdades que refletem na contemporaneidade, assim o passado atua no presente entre homens e mulheres.

O script sexuado de progressão nas carreiras foi conceituado por Le Feuvre e Lapeyere (2005). Esse conceito parte da ideia de que os homens são competentes na esfera profissional, não precisando demonstrar isso, ao passo que as mulheres precisam provar que são competentes profissionalmente. É desenvolvido o pressuposto de que elas não possuem disponibilidade total para o trabalho, atribuindo-se apenas a elas a conciliação da vida familiar e profissional. Os homens ficariam dispensados desta conciliação, constituindo o perfil desejado de dedicação integral à profissão.

A carreira de delegado de polícia, que é o foco deste trabalho, foi tradicionalmente um reduto masculino, ou, como nos mostra Le Feuvre (2008), um “bastião masculino”. Atributos masculinos como força, 
coragem e autoridade são ressaltados para lidar com o mundo do crime. É nesse contexto que o presente estudo analisou como as mulheres conseguiram adentrar nessa profissão marcadamente masculina, como foram desenvolvidas as relações entre os gêneros e o impacto disso para o profissionalismo.

Ao comparar modelos de feminização das profissões na França e na Grã-Bretanha, Le Feuvre (2008) indica duas teses para se pensar carreiras "burocráticas" e carreiras "profissionais". Uma delas pauta-se na ideia de que a feminização em estruturas burocráticas ocorre em consonância com o fato de essas estruturas assegurarem direitos sociais, o que nas unidades de exercício liberal seria mais difícil. A segunda tese discorre que as tendências estruturais de uma profissão e a forma de concentração dela podem estar relacionadas ao fato de as mulheres optarem mais pelo exercício liberal em detrimento das carreiras burocráticas. Segundo a autora, a trajetória profissional em uma carreira burocrática é baseada na dedicação de tempo integral, e a atividade liberal possibilita uma maior flexibilização do tempo.

Durante as entrevistas realizadas para o presente estudo, foi possível perceber pela fala das delegadas que o fato de ser mulher e conciliar a profissão e a esfera privada das relações é uma tarefa árdua, o script sexuado marca a trajetória profissional destas profissionais. Dentre as entrevistadas, a maioria apresentava um perfil etário mais jovem, estando representadas em maior número pelas solteiras. Segundo a fala de algumas entrevistadas, as mulheres que preferem ter uma vida mais tranquila e estável optam por trabalhar nas DDMs, nos plantões policiais ou em cargos administrativos, pois nestes lugares elas poderiam distribuir melhor o tempo, entre a vida profissional e a vida pessoal e familiar.

Atualmente, o profissionalismo é marcado por algumas transformações de ordem quantitativa e qualitativa, entretanto essas alterações não podem transmitir a ideia de que no mundo profissional prevalece a igualdade de oportunidades entre os gêneros. $\mathrm{O}$ profissionalismo como uma ideologia e uma prática de monopolização de mercados expandiu-se no final do século XIX e consolidou-se no século XX. Esta forma alternativa de organização do trabalho (Freidson, 1998) seria o motor das assimetrias nas relações de poder entre os gêneros.

O profissionalismo que é reconhecido pela ideologia da neutralidade passa a ser problematizado com base nas relações entre os gêneros. O intuito do presente trabalho, nesse sentido, é pensar como se operam as desigualdades nessa forma de organização do trabalho. A forma como o profissionalismo incorpora as mulheres na profissão de delegado é um ponto-chave para o estudo. O monopólio do exercício da profissão, as neutralidades da expertise, as relações de confiança entre leigo e profissional, a especialização e a dedicação integral à profissão formam um conjunto de características que reproduz a segregação sexual do trabalho. Em contrapartida, as conquistas das mulheres em termos de direitos e espaço no mundo profissional superior abrem oportunidades de empoderamento (Scott, 1998), diminuindo a assimetria e a subordinação feminina (Bonelli et al., 2008).

Bonelli et al. (2008), em estudo sobre a profissionalização de advogadas e advogados nos escritórios de São Paulo, indicam que o profissionalismo concebido no final do século XIX e início do século XX incorpora as advogadas segregadas pela forma como lidam com o gênero. As profissionais que conseguem superar a barreira para ascender na profissão, tornando-se sócias das grandes bancas advocatícias, são também as bem-sucedidas na realização do trabalho ideológico e de administração das emoções, enquadrando-se nos valores masculinos da profissão. Nesse sentido, a 'igualdade' de oportunidades é apenas percebida de forma concreta por meio da masculinização do ideário e da prática profissional. O discurso das profissionais que ascenderam tem como base a valorização da competência profissional, sendo uma prova do sucesso alcançado. Por outro lado, neutralizar a subjetividade do gênero e seu impacto no profissionalismo e no cotidiano é a forma que elas encontraram de mostrar que são tão capazes quanto eles. O conceito de apagamento de gênero empregado no estudo sobre advogadas será utilizado para se pensar o caso das delegadas de polícia.

Para Hirata e Kergoat (2007), a divisão sexual do trabalho é uma forma de divisão do trabalho social que é resultado das relações sociais entre os sexos, sendo também um fator essencial para a sobrevivência da relação social entre os sexos. Esse modelo é marcado pela designação dos homens à esfera produtiva e das mulheres, à reprodutiva e, somado a isso, a apropriação pelos homens das funções com maior valor social adicionado (políticos, religiosos, militares etc.). A divisão social do trabalho teria dois princípios organizadores, o de separação e o hierárquico, sendo o princípio de separação pautado na existência de trabalhos de 'homens' e de 'mulheres'. O princípio hierárquico designa o grau de importância e prestígio que um trabalho desempenhado por um homem tem, em detrimento de um trabalho realizado por uma mulher. No caso específico das Delegacias de Defesa da Mulher, algumas entrevistadas avaliam que as funções desempenhadas pelas delegadas nesses órgãos são associadas ao lado "feminino", tendo as mulheres contribuído para uma nova configuração na instituição policial, já que elas trouxeram atributos como serem detalhistas, atenciosas e mais humanas.

O profissionalismo reflete também as dificuldades de ingresso a posições mais elevadas dentro da carreira ocupada, o que é denominado glass ceiling, o "teto de vidro", uma alusão à barreira invisível que dá 
uma enganosa aparência de igualdade de oportunidades de ascensão na carreira, mas barra o acesso delas aos cargos mais elevados na hierarquia profissional (Barbalho, 2008).

Este artigo realiza uma discussão sobre a presença das mulheres na profissão de delegado de polícia, uma carreira tipicamente masculina que associa traços como força, virilidade e o manuseio de armas para lidar com o 'mundo do crime'. A carreira de delegado(a) de polícia foi tradicionalmente marcada pela presença masculina. É nesse contexto que se buscou analisar como as mulheres conseguiram adentrar nessa profissão e como foram desenvolvidas as relações entre os gêneros. O trabalho desenvolve quatro argumentos centrais ${ }^{1}$. O primeiro é que a Delegacia de Defesa da Mulher, em sua fase de implantação inicial, possibilitou uma 'reserva de mercado' para as profissionais da área, impactando em um maior ingresso de mulheres para o cargo de delegado de polícia, entretanto contribuiu para que houvesse uma 'subalternização' das funções desempenhadas por elas, já que essa Delegacia é percebida pelo grupo profissional como uma ramificação da polícia, onde são realizados trabalhos sociais e assistenciais. Assim, o estudo parte da ideia de que a 'reserva de mercado' assegurada pelo profissionalismo, quando chega para as mulheres torna-se gueto. O trabalho realizado em uma DDM é visto pelas delegadas como um "atravancamento" para a carreira; desse modo, se, por um lado, a implantação dessa política pública canalizou um maior número de mulheres para trabalharem nesses órgãos, por outro, gerou um processo de 'aprisionamento' das trajetórias profissionais delas.

Detectou-se, na fala das delegadas, que os delegados não enxergam com "bons olhos" o fato de ter que trabalhar em uma DDM, o que acontece também com algumas delegadas que partilham dessa mesma ideia. Em contrapartida, a profissional encontra no trabalho realizado na DDM uma alternativa para conciliar profissão e vida familiar, em um ambiente menos hostil e lidando com situações consideradas mais previsíveis. Delegados e delegadas que trabalham, especificamente, em plantões policiais também têm mais tempo para organizar sua vida familiar, como também sua vida profissional, isso porque os profissionais que se encontram nos plantões trabalham um dia e têm 72 de folga até retornarem para sua função.

O segundo argumento pauta-se nos conceitos de apagamento de gênero e de essencialização positiva para operacionalizar como se dão as trajetórias profissionais de delegadas e delegados. O fato de as mulheres estarem ingressando cada vez mais nos concursos para a carreira reforça a ideia de que, na profissão, elas precisam mostrar-se tão competentes quanto eles, e isso se dá mediante o apagamento de todas as diferenças marcadas pelos gêneros. As delegadas adotam uma 'postura' para traçarem sua trajetória profissional, entretanto tal modo de se portar no ambiente de trabalho é pautado em valores masculinos dominantes. Por outro lado, as profissionais tentam demarcar o tempo todo que, para ser delegada, não é preciso ser 'masculina', 'truculenta', características essas, que moldam a imagem que a instituição policial possui perante a sociedade. $\mathrm{O}$ estudo detectou que as delegadas travam um jogo no qual elas 'jogam' com dois polos, de um lado elas recorrem ao que foi definido pela pesquisa como essencialização positiva, isto é, buscam utilizar características, atributos tipicamente femininos, para conseguirem o reconhecimento profissional. Nesse sentido, ser mais humana, mais atenciosa, menos truculenta seria uma forma de as profissionais serem reconhecidas por meio de características que são vistas como positivas para a profissão e para a instituição policial. O outro polo do jogo travado na carreira é o apagamento de gênero ${ }^{2}$, em que as delegadas tentam apagar todas as diferenças percebidas como negativas e as barreiras enfrentadas pelo gênero.

Assim, um dilema é colocado para essas profissionais, isso porque a essencialização positiva realizada pelas delegadas dificulta operar o apagamento das diferenças vistas como negativas. Este é o jogo articulado pelas delegadas: de um lado, temos a essencialização positiva e, do outro, o apagamento de gênero negativo. Entretanto, o resultado disso é que uma ação deixa a outra mais vulnerável, implicando um dilema para a profissão. As delegadas encontram-se na base da hierarquia profissional, contribuindo para dar sustentação para a profissão. Esse fato foi percebido pelas entrevistadas como um processo que tenderá a igualar a proporção de homens e mulheres, futuramente. Para as profissionais, o ingresso tardio das mulheres nesse cargo seria um dos motivos pelo qual elas ainda não teriam grande representatividade nos altos postos da carreira.

$\mathrm{O}$ terceiro argumento pauta-se no conceito de glass ceiling ("teto de vidro"), que seria uma barreira invisível que impediria as mulheres de ascenderem aos altos postos da profissão (Bonelli et al., 2008). Esse conceito é muito utilizado nos estudos sobre a feminização de carreiras jurídicas (Barbalho, 2008). No caso específico das delegadas de polícia do estado de São Paulo, elas encontram-se menos representadas no topo da profissão, que é a Classe Especial. As profissionais concentram-se mais na base da carreira, que é representada pelas $5^{\mathrm{a}}$ e $4^{\mathrm{a}}$ Classes. Elas reconhecem o fato da baixíssima representatividade que têm nos altos postos profissionais,

1 Este artigo é resultado da pesquisa de dissertação de mestrado intitulada As delegadas de polícia de São Paulo: profissão e gênero, desenvolvida pela autora de 2007 a 2009, no Programa de Pós- Graduação em Sociologia da Universidade Federal de São Carlos.

2 Ver o estudo de Bonelli et al. (2008). 
todavia não percebem isso como um impedimento para ascensão profissional delas.

O quarto argumento é estabelecido a partir do conceito de dirty work desenvolvido por Hughes (1962). Nesse sentido, o dito "trabalho sujo" é articulado na profissão de delegado de polícia como uma forma em que para aquela/e profissional se destacar é preciso inferiorizar o outro. Delegadas e delegados de polícia, ao avaliarem as DDMs, culpam a vítima pelo não reconhecimento do status profissional deste órgão. No modelo profissional, muitas vezes atribui-se aos leigos a culpa dos problemas enfrentados na carreira. Assim, no caso dessas delegacias especializadas, o fato de as atribuições serem associadas muito mais a trabalhos sociais e assistenciais que efetivamente criminais é responsabilidade das vítimas (leigos) que procuram ajuda nas DDMs.

O estudo detectou que as DDMs contribuíram para um maior ingresso de mulheres na profissão, entretanto, desde seu projeto de idealização até os dias atuais tais órgãos sofrem grandes problemas para a solidificação de sua imagem e de suas atribuições. Diante disso, os objetivos do trabalho foram os seguintes: analisar a presença das mulheres na profissão, discutir a imagem dessa delegacia dentro da instituição policial, comparando-a com os Distritos Policiais, e avaliar como se dão as relações entre os gêneros, verificando o impacto disso para a profissão. A pesquisa que resultou neste artigo utilizou como recorte espacial a cidade de São Paulo, dado que a primeira Delegacia de Defesa da Mulher foi implantada neste município. Adotou-se como metodologia de pesquisa o trabalho de campo em Delegacias de Defesa da Mulher e em Distritos Policiais, com o intuito de perceber qual o olhar que as profissionais e os profissionais tinham da atividade, e de que forma a associação entre gênero e profissão havia contribuído para a construção da imagem dessa delegacia. Foram realizadas ao todo 12 entrevistas, sendo 9 com delegadas e 3 , com delegados, a fim de que se pudesse traçar uma análise comparativa sobre as trajetórias profissionais, assim como as percepções acerca da profissão.

\section{A profissionalização de delegadas e delegados de polícia na cidade de São Paulo e a reserva de mercado das DDMs}

No período de realização da pesquisa, na cidade de São Paulo existiam 93 Distritos Policiais, uma Delegacia do Idoso, uma Delegacia do Metrô, duas
Delegacias dos Crimes Fazendários, uma Delegacia de Acidentes de Trabalho e uma Delegacia de Meio Ambiente. As Delegacias de Defesa da Mulher contavam com nove unidades distribuídas pelo município e com o Serviço Técnico de Apoio às DDMs, que é um órgão que faz uma mediação entre essas delegacias e a Delegacia Geral de Polícia, além de coordenar essas unidades. De acordo com dados da Assessoria de Imprensa das Delegacias de Defesa da Mulher do Estado de São Paulo, há, na Capital, 15 delegadas de polícia distribuídas nessas delegacias, não há homens. No estado de São Paulo, nas Delegacias de Defesa da Mulher, há 135 delegadas, o que representa 89,4\% (incluindo as 15 da Capital) e 16 delegados, cerca de $10,6 \%$, totalizando 151 delegados de polícia de ambos os sexos ${ }^{3}$. O estado de São Paulo conta com 129 DDMs, sendo 9 na Capital, 13 na Grande São Paulo e 107 no interior.

Tabela 1 - Delegados de polícia das DDM's do Estado de São Paulo segundo gênero, 2008

\begin{tabular}{l|c|c}
\hline \multirow{2}{*}{ Gênero } & \multicolumn{2}{|c}{ Delegados } \\
\cline { 2 - 3 } & n. & $\%$ \\
\hline Feminino & 135 & 89,4 \\
Masculino & 16 & 10,6 \\
Total & 151 & 100,0 \\
\hline
\end{tabular}

Fonte: Assessoria de Imprensa das Delegacias de Defesa da Mulher.

Os dados da Tabela 1 confirmam um dos argumentos deste trabalho de que a DDM contribuiu para que houvesse uma 'canalização' das mulheres para atuação nesses órgãos. Para Musumeci e Soares (2005), o ingresso de mulheres nas polícias de vários países esteve associado a três eixos, um deles que diz respeito à necessidade de substituir a baixa causada nos efetivos masculinos durante os períodos de guerras, o segundo, que se refere às reformas institucionais para modificar a imagem da polícia, e, por fim, o terceiro, que seria uma resposta às pressões pela democratização de uma área de trabalho fechada para a participação feminina. As autoras ressaltam que, no Brasil, a inclusão do efetivo feminino teve motivações internas que seriam uma resposta à opinião pública e à sociedade civil, dado que a imagem da polícia militar estava muito associada ao período da ditadura militar. O desejo de 'humanizar' essa organização seria uma forma de contra-argumentar essa imagem negativa. No caso da profissão de delegado de polícia, esse processo de humanização é visto pelas mulheres como um fator positivo adquirido com o ingresso delas na instituição policial. 
Os dados apresentados na Tabela 2 mostram que o número geral de delegadas representa $16,1 \%$ do total de integrantes da profissão, no estado de São Paulo. A profissão continua esmagadoramente masculina com $83,9 \%$, entretanto o percentual de mulheres vem aumentando progressivamente. Bonelli (2003) desenvolve o argumento de que onde a institucionalização da profissão se iniciou mais cedo, que é o caso de São Paulo. que regulamentou a carreira em 1905, a taxa da presença feminina é menor que os casos em que tal processo ocorreu mais tarde. Em casos como o estado da Bahia, onde a institucionalização da profissão se deu mais tardiamente, o número de mulheres chega a $47,4 \%$ do total de delegados.

Tabela 2 - Delegados de polícia segundo o gênero. São Paulo, 2008

\begin{tabular}{l|r|r}
\hline \multirow{2}{*}{ Gênero } & \multicolumn{2}{|c}{ Delegados } \\
\cline { 2 - 3 } & n. & $\%$ \\
\hline Masculino & 2.716 & 83,9 \\
Feminino & 521 & 16,1 \\
Total & 3.237 & 100,0 \\
\hline
\end{tabular}

Fonte: Delegacia Geral de Polícia, 2008

De acordo com dados levantados pelo Ministério da Justiça e pela Secretaria Nacional de Segurança Pública, em 2004, após quase vinte anos de criação desse órgão, a maioria das Delegacias de Defesa da Mulher localizava-se na Região Sudeste, concentrando-se no estado de São Paulo, cerca de 40\% do total das DDMs. No Brasil, havia, em 2004, em torno de 289 dessas delegacias. Essa pesquisa constatou que, nas 289 DDMs, há um total de 3.093 funcionários, sendo 2.138 do sexo feminino e 955 , do sexo masculino. Isto representa que aproximadamente $69 \%$ do efetivo, nessas delegacias, são mulheres. A análise do perfil hierárquico dos quadros que trabalham nas DDMs estudadas mostra que quase não há desigualdade em relação à composição sexual das categorias (papiloscopistas, escrivães, escreventes, carcereiros). No entanto, as hierarquias superiores, compostas por delegados, inspetores, investigadores, detetives e agentes, são formadas maciçamente por profissionais do sexo feminino, o que evidencia o argumento levantado pelo presente trabalho de que as DDMs contribuíram para canalizar mais as delegadas de polícia para estes órgãos do que os delegados, porém o ingresso delas marca o lugar ocupado nessa delegacia como 'gueto'. Já com relação ao perfil racial, os brancos constituem maioria nos cargos hierárquicos mais elevados, nos cargos inferiores da hierarquia, brancos e não brancos são distribuídos de forma equilibrada. Para os delegados de polícia, os não brancos (pretos, pardos, amarelos e indígenas) representam 5\%. É destacado que, na cate- goria dos não policiais, a maioria também é composta por mulheres brancas.

Os Distritos Policiais (DPs) estariam configurados como organizações mais prestigiosas dentro do universo policial, já que nesses órgãos ocorrem investigações e aberturas de inquéritos que englobam todas as áreas da parte criminal, não apenas a violência contra a mulher, como no caso das DDMs. Assim, vemos estabelecido um modelo de distinção entre as funções desempenhadas. As mulheres desempenhariam o chamado dirty work ${ }^{4}$, ao passo que os homens realizariam os trabalhos vistos como mais importantes pela instituição policial. Utiliza-se aqui o conceito de "trabalho sujo" desenvolvido por Hughes (1962). A percepção que os delegados têm acerca do papel das DDMs seria a de que as delegadas deveriam desempenhar o "trabalho sujo" a ser realizado para "filtrar" as situações indesejadas pela instituição policial. Nesse sentido, as mulheres deveriam realizar algumas funções que são consideradas como 'não-qualificadas' no interior da profissão. Os homens 'deixariam' para as delegadas aqueles trabalhos 'maçantes' e que desprestigiam a profissão de delegado de polícia, já que a afastam do seu ideal de punição e de aplicação da lei. Nesse sentido, o trabalho do outro, ou melhor, o trabalho das delegadas nas DDMs é desqualificado com o intuito de destacar e valorizar a estruturação e atuação dos DPs.

Segundo Massuno (2002), o governo do estado de São Paulo, ao criar a Delegacia de Defesa da Mulher, atendeu a reivindicação do movimento feminista que era favorável à "criminalização" da violência contra a mulher, e de forma indireta contribuiu para a igualdade de oportunidades de gênero. Esse fato trouxe como consequência um aumento no número de policiais mulheres na Polícia Civil do Estado de São Paulo. Este estudo vai ao encontro da ideia de que a criação da Delegacia de Defesa da Mulher possibilitou um ingresso maior de mulheres na carreira de delegado, entretanto discorda que realmente exista essa igualdade de oportunidades de gênero. Para isso, buscou-se verificar como se dão as relações entre homens e mulheres na profissão, como se dá a distribuição hierárquica na profissão sob o recorte de gênero, e qual a estrutura e a posição dessa delegacia dentro da instituição policial.

O estudo de Brocksom (2006) sobre a Delegacia de Defesa da Mulher de São Carlos constatou que esta é caracterizada como uma "delegacia de papel”, já que este órgão estaria associado à burocratização e à pouca ação. Essa imagem é atribuída, sobretudo, pelas profissionais que ali trabalham: investigadoras, escrivãs e delegada. Segundo as profissionais, o trabalho na DDM não é reconhecido, o que gera perda de prestígio do 
órgão e desestímulo para as mesmas. Em São Carlos, o funcionamento da DDM é de segunda a sexta-feira, sendo que nos finais de semana os casos de violência contra a mulher devem ser registrados no plantão-piloto da Delegacia Seccional do município. Entretanto, as vítimas são orientadas pelas equipes desse plantão a procurarem a DDM durante seu período normal de atendimento. A autora retrata como as mulheres que procuram atendimento nesse plantão são tratadas com descaso. Isso mostra como se opera a divisão sexual do trabalho na Polícia Civil, o que será aprofundado neste trabalho. Para Brocksom, as DDMs são vistas como delegacias de papel, já que os casos são, na maioria das vezes, arquivados. Em contrapartida, os DPs são vistos pelos profissionais da área como um órgão atuante onde os casos são investigados e solucionados.

Em pesquisa sobre as DDMs, Gregori (2006) aponta que os obstáculos enfrentados para a consolidação dos serviços prestados pelas DDMs resultam de um processo de subvalorização dessas delegacias dentro da instituição policial e de seus quadros dirigentes. Isso se deve porque os crimes que são atribuições dessas delegacias são tidos como de menor potencial ofensivo à sociedade. Para a autora, os conflitos que desencadeiam esses crimes são percebidos pela Polícia Civil como um tipo de atendimento que vai além das atribuições técnicas dos agentes policiais, exigindo tratamento assistencial fornecido por profissionais especializados em outras áreas disciplinares. Gregori conclui que nesses órgãos prevalece um paralelismo institucional, em que outros órgãos de atendimento realizam uma atuação isolada, não interagindo com as DDMs. Isso mostra que "A fragilidade na consolidação de um atendimento policial especializado e articulado ao movimento trouxe ainda maior dificuldade na definição do objeto da intervenção" (Gregori, 2006, p. 66).

Para Gregori, de acordo com a cultura jurídica que informa e orienta o trabalho nas delegacias, define-se que a função da polícia judiciária é a de investigar crimes baseado no "princípio de legalidade". Dessa forma, não há crime sem lei anterior que assim o estabeleça. As delegacias têm suas atribuições baseadas em tipificações penais, sendo que a violência contra mulher (familiar, doméstica ou de gênero) não expressa um formato jurídico determinado pela lei criminal. Segundo a autora,

O que é descrito como tipo penal, implicando uma classificação (lesão corporal, ameaça, atentado violento ao pudor, calúnia e difamação etc.), depende da interpretação que a agente (e, no caso concreto, a delegada ou a escrivã) tem da queixa denunciada pela vítima. (Gregori, 2006, p. 66)
Durante a minha observação de campo nas DDMs de São Paulo, esse 'desprestígio' foi percebido, sobretudo quando os agentes dos DPs apareciam na $\mathrm{DDM}^{5}$. Durante uma visita minha a uma DDM, presenciei uma investigadora de um DP, que funcionava embaixo daquela delegacia especializada, solicitar de forma ríspida que a auxiliar de limpeza fizesse primeiro o trabalho no Distrito Policial, isso porque a DDM estaria sempre vazia e não tinha tanta necessidade quanto o distrito, já que este teria muito mais rotatividade. $\mathrm{O}$ desprestígio é associado tanto às atribuições que esses órgãos possuem, como à falta de consolidação legal das DDMs.

Maria Cândida Bahia (2002) indica em seu estudo sobre as delegadas de polícia da Bahia algumas características da socialização do papel feminino que exercem influência nas delegacias. A autora também coloca referências acerca da reprodução dos valores dominantes na profissão como a especialização das atribuições de acordo com o gênero. Assim, a função social, assistencial e comunitária estaria mais ligada ao domínio feminino e a repressiva, ao masculino. Essa função assistencial seria representada pelas DDMs, ao passo que a repressiva seria representada pelos DPs.

A DDM tem sua imagem muito atrelada à ideia de um órgão assistencial, onde as delegadas desempenhariam funções assistenciais e de atendimento psicológico. Entretanto, as delegadas destes órgãos vêm buscando delimitar suas atribuições e competências, na tentativa de consolidar o prestígio da atuação profissional nessas delegacias. Essa luta por reconhecimento gera um processo de desgaste emocional para as profissionais ${ }^{6}$.

Tornar o gênero invisível é marcante na profissão, entretanto isso varia nas falas das entrevistadas. Entre as delegadas entrevistadas, há um consenso no discurso de que na carreira existe uma igualdade de oportunidades de gênero. Contudo, em suas trajetórias profissionais a discriminação de gênero foi descrita em alguns momentos da carreira. Dessa forma, é possível perceber que elas enfrentam barreiras pelo fato de serem mulheres, entretanto o que se altera é a importância dada por cada entrevistada. Em linhas gerais, nota-se que aquelas profissionais que são titulares e estão mais tempo na carreira, de certa forma, aderem ao discurso de que a polícia e os pares respeitam e valorizam o trabalho das profissionais, mencionando que no passado sofreram algum tipo de resistência na profissão, mas, atualmente, as transformações trazidas pelo ingresso das mulheres no mercado de trabalho alteraram esse quadro. O fato de se estar na profissão há alguns anos e não se ter chegado a posições mais altas na hierarquia profissional não é visto como um de- 
sestímulo para elas, que, em contrapartida, argumentam que isso pode ser revertido e que as profissionais podem ficar mais representadas nos postos de chefia. Tanto para as delegadas, quanto para os delegados, a política convencional presente na profissão é um ponto negativo, porque, segundo eles, as promoções ainda estão muito ligadas às redes sociais estabelecidas na carreira.

A renovação dos quadros da profissão também é indicada pelas delegadas, sendo avaliada como um ponto positivo para a entrada das mulheres, já que os profissionais mais antigos tinham uma visão mais tradicional e conservadora sobre a feminização da carreira. $\mathrm{O}$ fato de elas estarem entrando cada vez mais nos concursos para a profissão também é visto como um fator positivo pelas profissionais, já que isso seria uma prova de que as mulheres podem desempenhar as mesmas funções que os homens, sendo tão competentes quanto eles. O fato de as mulheres estarem, cada vez mais, ganhando as primeiras colocações nos concursos para ingressar na carreira ${ }^{7}$ foi lembrado pelas delegadas.

\section{Estratégias profissionais: um dilema para a carreira?}

Diana, 37 anos, solteira, sem filhos, natural de Presidente Prudente, é delegada assistente de um Distrito Policial pertencente à $2^{\text {a }}$ Classe, e está há 15 anos na profissão. A entrevistada não pensava em ser delegada de polícia, e sim juíza, ela buscava a estabilidade de um cargo público. A delegada disse que, depois que entrou para o cargo, não prestou outros concursos. Ela diz que passou a gostar da profissão, pois é uma carreira envolvente, seu maior interesse é pela parte investigativa, já que a investigação expressaria uma das principais atribuições da profissão de delegado de polícia. Como profissional, ela chama atenção para o fato de que a(o) delegada(o) de polícia lida com a lei, é de sua competência aplicar a lei, mas isso fica fragilizado quando, em diversas situações, o público procura uma delegacia para resolver problemas sociais e humanitários. Aqui, podemos aplicar o conceito de dirty work, pois vemos na fala de Diana que ela responsabiliza as vítimas que procuram os serviços das delegacias por não entenderem o que é da alçada da profissão. O leigo seria o 'culpado' pelo não reconhecimento do status profissional. Nesse sentido, percebe-se que o profissionalismo entra em choque ao ter que lidar com questões que não são de sua jurisdição e competência, o que tem um impacto direto na visão que o profissional tem sobre certas atribuições, e funções da polícia como instituição.

Um dilema, a partir disso, é travado, se a grande contribuição das mulheres para a polícia seria a de instaurar um processo de humanização da instituição, como muitas profissionais rejeitam esse lado mais 'humano' e 'assistencial' da instituição? A priori, pode-se dizer que tanto delegadas, quanto delegados, partilham de um ethos profissional, que, por sua vez, tem um peso muito maior sobre o gênero, do que vice-versa. Delegadas e delegados de polícia passaram por um concurso público, no qual foram selecionados, posteriormente receberam treinamento teórico e prático para exercer a profissão. Desse modo, mesmo as profissões não partilhando de uma identidade homogênea, e sendo marcadas por conflitos, elas possuem um ethos profissional que lhes é comum.

Diana, que é assistente de um Distrito Policial, ressalta que ser mulher e delegada não é uma tarefa fácil, porém isso para ela não é um problema, dado que não é casada, nem tem filhos, e diz que não pensa em ter. Por outro lado, ela relata que muitas colegas sofrem para conseguir conciliar a vida profissional e a vida pessoal. Segundo a delegada, as mulheres que trabalham como titulares, assistentes, ou na parte investigativa têm que saber trabalhar seu tempo, a dedicação é integral, e muitas vezes, não se tem um horário fixo. Ela conta que tem dias em que ela entra às oito horas da manhã e não tem horário para sair, mas deixa bem claro que não se queixa, pois gosta do que faz e acredita que a mulher tem que se empenhar mais na profissão, pois é mais cobrada. Para Diana, como o horário da profissão é incerto, muitas delegadas optam por trabalhar em setores administrativos, nas Delegacias de Defesa da Mulher, ou mesmo nos plantões policiais, já que estes permitiriam à profissional organizar melhor seu tempo, por possuírem horários mais definidos. A delegada, nesse sentido, realiza novamente o enquadramento do 'trabalho sujo'. Curioso é que o plantão policial aparece como alternativa para aquelas profissionais que querem otimizar seu tempo, muitas optam por trabalhar em plantões noturnos e nos finais de semana, porque a cada plantão dado se tem 72 horas de folga, o que possibilitaria destinar mais atenção no acompanhamento dos filhos e da família.

Então, o horário para a mulher que trabalha como assistente, ou mesmo na titularidade, ou num setor de investigação, é complicado porque não é certo. O plantão é cansativo, quando ele é noturno, mas os delegados que são plantonistas conseguem adequar o seu horário, não é muito bom porque se trabalha final

7 Segundo a Secretaria de Segurança Pública do estado de São Paulo, dos(as) delegados (as) que tomaram posse do cargo em janeiro de 2008 , as mulheres estavam nas duas primeiras colocações. 
de semana, mas se tem os dias de folga e você pode se programar. A gente que trabalha na assistência ou na chefia você não pode se programar, e não significa que você tenha o final de semana livre, às vezes, acontece alguma coisa e você tem que vir para a delegacia trabalhar. Então para a mulher o horário de chefia e do setor de investigação é complicado, eu gosto, mas muitas mulheres, a maioria, preferem trabalhar em plantões, nas delegacias da mulher ou em departamentos administrativos, porque é de segunda a sexta das nove da manhã às dezenove horas, e é um horário certo, de sábado e domingo é folgado. É complicado ter um trabalho que exige muito do seu tempo, pois ele acaba interferindo na sua vida social, principalmente se você tem filhos, no meu caso eu não tenho filhos, e nem pretendo ter, então é mais fácil. Mas quando a pessoa é casada e tem filhos é difícil, eu tenho uma colega delegada que trabalha no plantão, ela adora trabalhar no plantão, ela tem um filho de onze anos e ela precisa acompanhar o filho, se ela trabalhar na assistência ela não tem horário para o filho porque não tem horário para sair. (Diana)

Denise, 43 anos, casada, sem filhos, natural de Mogi das cruzes, delegada titular da $1^{\text {a }}$ Classe de uma DDM, relata que sua experiência profissional de mais de vinte anos foi marcada por passagens nas Delegacias de Defesa da Mulher do interior de São Paulo. Ela menciona o fato de como o processo de idealização e implantação das DDMs teve visibilidade na mídia e na sociedade, de um modo geral, dado o contexto de surgimento desses órgãos, que contou com o apoio do movimento feminista da época. Entretanto, ressalta que sua experiência no interior foi marcada por algumas resistências, sobretudo na organização policial, associadas ao fator de que prevaleciam profissionais mais tradicionais que não viam com "bons olhos" a presença do outro (no caso as mulheres). O preconceito com relação à DDM e com as profissionais que ali trabalhavam era presente. Em contrapartida, foi apontado pela entrevistada o processo de transformação da profissão com o ingresso de profissionais mais jovens, contribuindo para uma pluralização nos quadros profissionais e, consequentemente, para diminuição do preconceito com relação às mulheres e à Delegacia da Mulher.

A delegada menciona que, antes, a DDM era vista como uma delegacia provisória, um órgão que não seria definitivo, já que foi resultado de um contexto de luta contra a violência sofrida pelas mulheres. Essa delegacia teria ganhado força de atuação com a criação da Lei Maria da Penha (Lei n. 11.340). Percebe-se uma luta por reconhecimento das atribuições dessa delegacia especializada que tem uma imagem frágil perante a instituição policial. Segundo a delegada, a Delegacia da Mulher era vista, no passado, como um órgão que não fazia parte da polícia, sendo associada a ela a imagem de uma instituição assistencial, em vez de punitiva. Se comparada aos demais segmentos da Polícia Civil, a Delegacia da Mulher tem sua importância minimizada. No jargão policial, costuma ser apelidada de delegacia "seca" ou de "papel", porque não prende e não pratica grandes batidas e perseguições, ações associadas ao masculino, ao público e ao forte. É também associada a um "lugar de mulher" e uma "cozinha da polícia", onde as mulheres se reúnem para chorarem suas mágoas (Izumino, 1998).

Denise afirma que hoje em dia não existe mais preconceito com relação à Delegacia da Mulher, embora haja um caso ou outro ainda dentro do mundo policial. Ao ler essa entrevista, é preciso levar-se em consideração onde e como esse discurso foi produzido; no caso da profissional apresentada, ela se insere em uma instituição policial, partilhando valores comuns presentes na Polícia Civil. O impacto do ethos profissional sobre o gênero, nesse caso, é maior do que o inverso. A entrevistada, como uma profissional que tem sua trajetória na polícia há cerca de vinte anos, vê e percebe sua carreira como positiva, não enxergando entraves para a ascensão na profissão.

Segue um trecho da transcrição da entrevista fornecida pela profissional:

Quando eu entrei em 1987, parece que tinha cerca de 30 mulheres, não me recordo agora. Então realmente naquela época realmente tinha um pouco de machismo, preconceito, hoje já não mais. Hoje já existe mais mulheres na carreira, não vejo mais preconceito. Até com relação à Delegacia da Mulher existia preconceito, até hoje pode até existir, mas dentro da polícia já esta diminuindo bastante, mesmo porque os chefes da polícia mudaram, não são aquelas pessoas mais velhas, aquelas se aposentaram, hoje são pessoas mais jovens, mesmo porque no início da Delegacia da Mulher se achava que era uma delegacia temporária. Mas, hoje se viu que não, que pode ser até definitiva, ainda mais hoje com a Lei Maria da Penha. Mas realmente tinha bastante preconceito, antes se achava que a Delegacia da Mulher não era polícia, não tratava você como se fosse uma delegada, tratava você de forma diferente, como se fosse uma assistente social, e achavam que as ocorrências eram de menos importância. Hoje já não mais, eu não sinto mais nenhum preconceito, nem tanto machismo, acho que um caso ou outro, mas muito raro, e nem com relação à Delegacia da Mulher. (Denise)

Daniela, 34 anos, casada, sem filhos, com 12 anos de profissão, $1^{a}$ Classe, delegada titular de uma Delegacia de Defesa da Mulher, diz não perceber que a DDM é vista com preconceito, entretanto chama atenção para o fato de que este órgão desempenha um papel relevante, isso é uma forma de resistência à imagem dessa delegacia ser associada às funções mais assistenciais, e, portanto de menor prestígio. Para a delegada, as atribuições que cabem à DDM são extremamente impor- 
tantes para a sociedade. Ela vê como machismo o fato de se associar a profissão de delegado de polícia a uma atividade tradicionalmente masculina. Para tanto, ressalta a neutralidade da profissão ao mencionar que a sua principal atribuição é "aplicar a lei ao caso concreto". A profissional adota o discurso de que, para se impor respeito no âmbito profissional, é necessário ter uma postura firme, o que remete a operar o apagamento do gênero, entendendo que, para gerar respeito, é preciso adotar uma atitude tipicamente masculina e neutra. Daniela frisa que até mesmo na iniciativa privada as profissionais precisam adotar uma postura mais firme e incisiva. $O$ atendimento especializado é visto como positivo pela profissional, já que, para ela, as vítimas sentem-se mais confortáveis em serem atendidas por uma mulher. Porém, a delegada não coloca as DDMs em "pé de igualdade" com os outros órgãos da Polícia Civil. Ela aponta com entonação de contraste que na instituição policial existem homens que também atuam com compreensão.

Embora a sociedade veja como uma atividade tipicamente masculina, eu encaro essa colocação como um pouco de machismo porque o nosso trabalho ele é basicamente aplicar a lei ao caso concreto, então... Eu não vejo por qual razão..., tem todo um estigma, mas as mulheres vêm ganhando cada vez mais nos concursos públicos, houve uma época de baixíssima aprovação, mas isso vem sendo mitigado e as mulheres vêm ganhando terreno nesse campo. O ingresso de mulheres está praticamente paritário.

Eu acho que hoje a DDM está bastante mitigada, eu não vou colocar em pé de igualdade, eu não tenho sentido essa diferença, realmente eu acho..., talvez quando da implantação das DDMs pode ter havido um pouco de machismo, ser visto com olhos que não os corretos, mas eu não acredito hoje em preconceito. Eu acho que a gente desempenha um papel muito importante sim! Nós cuidamos de crianças de qualquer sexo, que sejam vítimas de qualquer tipo de violência física, moral ou sexual, e também de mulheres que muitas vezes não tem um atendimento condizente, não porque uma delegacia comum não dê..., ou que a pessoa que esteja lá, esteja despreparada é que lá cuida-se de todos os tipos de ocorrências e muitas vezes não se tem nem disponibilidade para se dar a atenção devida. Aqui na DDM é uma delegada titular, as minhas escrivãs e o único homem que atua aqui é o investigador.

Para Daniel, delegado plantonista, $1^{\mathrm{a}}$ Classe, cinquenta anos, casado, as delegacias especializadas são necessárias para se coibir crimes e discriminações com as minorias, entretanto ele chama atenção para o fato de que quando se trabalha "com um segmento da população que é discriminado, está se discriminando também". Apesar de sua fala, o entrevistado vê positivamente a implantação das delegacias especializadas, porém ressalta que o poder público deveria dar respaldo para tais órgãos. Ao ser perguntado se gostaria de trabalhar em uma dessas especializadas, particularmente na Delegacia da Mulher, o entrevistado mencionou que prefere os plantões policiais porque eles são mais dinâmicos, cada dia se tem uma coisa nova, e isso o instiga. Os homens são pronta minoria nas delegacias especializadas ${ }^{8}$, sobretudo na das mulheres. Os conflitos domésticos e familiares são vistos como uma variável constante que é permeada pelos mesmos princípios sempre, os casos encaminhados para uma DDM têm um fio norteador que são as relações privadas, tais como brigas entre marido e mulher, entre mulheres que vivem no mesmo lar.

Segundo o delegado, o ingresso cada vez maior das mulheres na profissão é visto como positivo, ele se diz fã das mulheres, e coloca que elas são mais dedicadas e têm mais percepção, diferente do homem, que é mais racional. Assim, as mulheres teriam esse lado racional, só que este seria permeado pelo lado emocional e intuitivo. Pode-se trazer para análise do discurso do entrevistado a questão da humanização da polícia instaurada pelas mulheres, como nos mostrou Musumeci e Soares (2005). O fato de se colocar características tipicamente femininas no espaço do mercado de trabalho também está presente nesta fala, assim, na profissão de delegado de polícia, as funções trazidas do lar seriam estendidas para a carreira (Barbalho, 2008).

A mudança na estrutura da instituição policial contribuiu para o maior ingresso de mulheres na profissão. Segundo Daniel, antes a profissão era marcada por pessoas sem nenhum conhecimento técnico e teórico, a imagem do delegado truculento, cheio de correntes, retratava a realidade da época. De acordo com o delegado, a mulher não se encaixaria nesse ambiente, caracterizado por ele como nefasto; ele mesmo não teria o perfil para a instituição. Entretanto, atualmente, a Polícia Civil renovou seus quadros, contribuindo cada vez mais para a entrada de profissionais qualificados. Isso seria fruto de um processo de profissionalização pelo qual vem passando a polícia brasileira, tanto a Civil quanto a Militar (Poncioni, 2008). O entrevistado ressalta que hoje mudou muito o perfil do profissional que entra para a carreira de delegado de polícia, são pessoas que valorizam o conhecimento técnico e científico e que investem em cursos de aperfeiçoamento, como pós-graduação, tanto stricto quanto lato sensu. Daniel relata que tem muitos colegas que, assim como ele, lecionam em universidades e faculdades, e 
que o cargo de delegado(a) plantonista contribui para isso. Ser 'delegado' ou ser 'delegada' de polícia tem diferença para o entrevistado, porque as mulheres que estão na profissão continuam sendo cobradas na esfera da casa, já os delegados não sofreriam essa pressão, são menos cobrados com relação aos afazeres domésticos e cuidados com a família. Segundo ele, o homem seria mais folgado, sobretudo o de origem latina. $\mathrm{O}$ entrevistado ressalta características tidas como femininas, realizando assim, uma essencialização positiva do ingresso das mulheres na profissão. Dessa forma, são atribuídas características para a mulher profissional, tais como ser caprichosa, intuitiva, dedicada. Essa essencialização da profissional traz a possibilidade de dar outra roupagem para a instituição policial.

A fala de Daniel tem relação com o que nos mostra Lombardi (2008). Para a autora, a limitação ascensional nas carreiras, sobretudo na engenharia, é marcante entre as trabalhadoras; um dos entraves para subirem ao topo da hierarquia faz parte da própria condição feminina, já que a mulher é vista em nossa sociedade como portadora da total responsabilidade pelo cuidado da família e dos filhos. Em seu estudo sobre as engenheiras, ela conclui que, entre todas as barreiras vivenciadas pelas profissionais no decorrer de suas carreiras, a maior tem sido a de assumir os postos de comando. Assim, dois fatores contribuiriam para isso. O primeiro tem relação com o papel desempenhado pelo grupo de engenheiros, denominado de o 'clubinho', que, por ser mais antigo, estrutura-se tendo como base as relações de solidariedade e de confiança. Em contrapartida, as mulheres engenheiras não estariam organizadas em 'clubinhos' femininos, o que impacta diretamente na ascensão das mesmas aos altos postos da profissão. O outro fator analisado pela autora é o de que as mulheres teriam algumas resistências para assumir os postos de comando, já que muitas não teriam disponibilidade de uma dedicação full time à profissão e à empresa por causa da família e dos filhos, e também por optarem por ficar preservadas de uma competição por tais cargos (Lombardi, 2008, p. 401).

\section{Considerações finais}

O aumento das mulheres com formação Superior traz a ideia da igualdade de oportunidades de gênero, pautadas no mérito, na dedicação e na competência, que são valores do profissionalismo. Entretanto, as diferenças de homens e mulheres no que diz respeito à ascensão aos postos mais elevados na hierarquia profissional muitas vezes são apagadas pelo discurso daquelas profissionais que chegaram ao topo de sua profissão. $\mathrm{O}$ custo emocional que o não reconhecimento das atribuições das DDMs traz é perceptível. A passagem naquele órgão é, muitas vezes, sentida e per- cebida como um entrave para a profissão. As palavras depreciativas utilizadas para caracterizarem essas delegacias traduzem o valor simbólico destinado a elas.

Por outro lado, essas profissionais suscitaram como principais motivações para o ingresso na carreira a estabilidade econômica, a oportunidade de ter um cargo público, que possibilita associar a vida pessoal com a profissional, e a atração pela profissão. Essa segunda motivação é mais presente para as profissionais que têm mais tempo na carreira, já que, para aquelas mais jovens, a profissão é vista como um sacerdócio, isso porque no início da carreira os profissionais dedicam horas nos plantões policiais, função essa que não é mais realizada por aqueles que estão há mais tempo na carreira. A profissão foi associada à de médico para reforçar seu compromisso social. Sabe-se também que as mulheres, em muitas situações, fazem opção por um cargo público porque estas encontram ambientes menos hostis e mais receptivos que na iniciativa privada.

$\mathrm{O}$ fato de as delegadas estarem ingressando cada vez mais nos concursos é visto de forma positiva para as profissionais. A grande contribuição das mulheres para a profissão seria o processo de humanização por elas instaurado. Em vários trechos das entrevistas, as delegadas demonstram que valorizam o fato de a lei ser aplicada a todos, indistintamente, sendo que todos os cidadãos que chegam nessas delegacias devem ser tratados de forma digna. Para se afirmarem no mundo profissional, elas recorrem aos princípios que regem o profissionalismo.

No caso da profissão de delegado de polícia o peso que se tem pelo fato da instituição policial reproduzir a divisão sexual do trabalho, em que as DDMs estariam mais aptas a realizar tarefas mais assistenciais, sendo responsabilidade dos DPs atuarem para punição efetiva, é muito grande. Como mencionado no início do trabalho, desde sua idealização a DDM sofre para estabelecer suas atribuições e funções, fatos que contribuem para uma imagem negativa perante a própria polícia, contudo as profissionais vêm também ganhando seu espaço no que diz respeito à consolidação da imagem do órgão. Um exemplo disso é a Lei Maria da Penha (Lei n. 11.340). Esse fato foi caracterizado por algumas delegadas das DDMs como tendo um grande impacto sobre a atuação destes órgãos e, consequentemente, sobre a profissão delas.

A carreira das delegadas apresenta um dilema: a essencialização positiva realizada por algumas delegadas inviabiliza operar o apagamento de gênero. Nesse jogo articulado, de um lado temos a essencialização positiva e do outro, o apagamento de gênero negativo, que acabam por fragilizar as profissionais envolvidas. O resultado desse placar é que uma ação deixa a outra mais vulnerável. O combate jogado entre as delegadas é uma saída consciente e intencional a que elas recorrem para serem reconhecidas profissionalmente, todavia, o dilema causado por esse jogo não é consciente, mas impacta na estruturação da profissão delas. 
O 'trabalho sujo' é utilizado na profissão de delegado de polícia como uma forma em que, para aquela(e) profissional se destacar, é preciso inferiorizar o outro. Algumas delegadas e delegados de polícia, ao avaliarem as DDMs, culpam a vítima pelo não reconhecimento de seu status profissional neste órgão. Repassar aos leigos a culpa dos problemas enfrentados na carreira é uma alternativa para não abalar o prestígio e o reconhecimento da profissão.

\section{Referências}

BAHIA, M.C. Mulheres no comando das organizações: um caso de polícia. Dissertação (Mestrado) - Universidade Federal da Bahia, Núcleo de Pós-Graduação em Administração, Salvador, 2002.

BARBALHO, R. M. A feminização das carreiras jurídicas e seus reflexos no profissionalismo. Tese (Doutorado) - Universidade Federal de São Carlos, São Carlos, 2008.

BONELLI, M. G. Perfil social e de carreira dos delegados de polícia. In: SADEK, M. T. (Org.). Delegados de polícia. São Paulo: Idesp, 2003.

BONELLI, M. G. Arlie Russell Hochschild e a sociologia das emoções. Cadernos Pagu, Campinas, v. 22, p. 357-372, jan./jun. 2004.

BONELLI, M. G. et al. Profissionalização por gênero em escritórios paulistas de advocacia. Tempo Social. Revista de Sociologia da USP, v. 20, p. 13, 2008.

BRASIL. Lei n. 11.340, de 7 de agosto de 2006. Disponível em: <http://www.planalto.gov.br/CCIVIL/_ Ato2004-2006/2006/Lei/L11340.htm>. Acesso em: 06 dez. 2007.

BROCKSON, S. A Delegacia de Defesa da Mulher de São Carlos, SP. In: DEBERT, G. G. et alii. (Orgs.) Gênero e distribuição da justiça: as delegacias de defesa da mulher e a construção das diferenças. Campinas: Núcleo de Estudos de Gênero Pagu/Unicamp, 2006. (Coleção Encontros). FEUVRE, N. Modelos de feminização das profissões na França e Grã-Bretanha. In: BRUSCHINI et al. (Orgs). Mercado de trabalho e gênero: comparações internacionais. Rio de Janeiro: Ed. da FGV, 2008.

FEUVRE, N. ; LAPEYERE N. Les Scripts sexues de carriere dans les professions juridiques em France. Knowledge, Work \& Society, v. 3 n. 1, p.103-125, 2005.

FREIDSON, E. O renascimento do profissionalismo. São Paulo: Edusp, 1998.

GREGORI, M. F. Delegacias de defesa da mulher de São Paulo e as instituições: paradoxos e paralelismos. In: DEBERT, G. G. et alii. (Orgs.) Gênero e distribuição da justiça: as delegacias de defesa da mulher e a construção das diferenças. Campinas: Núcleo de Estudos de Gênero Pagu/
Este artigo, longe de querer passar fórmulas para o melhor funcionamento da instituição policial, buscou analisar que o mundo profissional é passível de mudanças e uma forma delas ocorrerem é pela convivência e interação entre os gêneros, que resultam em novas práticas sociais. Entretanto, ressalta-se que o aumento efetivo da participação feminina na profissão de delegado de polícia não pode ser por si só um indicativo de igualdade de oportunidades de gênero.

Unicamp, 2006. (Coleção Encontros).

HIRATA, H.; KERGOAT, D. Novas configurações da divisão sexual do trabalho. Cadernos de Pesquisa, São Paulo, v. 37, n. 132, set./dez. 2007.

HUGHES, E. C. Good People and Dirty Work. Social Problems, v. X, p. 85-97,1962.

IZUMINO, W. P. Justiça e violência contra a mulher: o papel do sistema judiciário na solução dos conflitos de gênero. São Paulo: Annablume, 1998.

LOMBARDI, M. R. Engenheira e gerente: desafios enfrentados por mulheres em posições de comando na área tecnológica. In: BRUSCHINI et al. (Orgs.). Mercado de trabalho e gênero: comparações internacionais. Rio de Janeiro: Ed. da FGV, 2008.

MASSUNO, E. Delegacia de defesa da mulher: uma resposta à violência de gênero. In: BLAY, E. (Org.). Igualdade de oportunidades para as mulheres: um caminho em construção. São Paulo: Humanitas, 2002.

MINISTÉRIO DA JUSTIÇA. Secretaria Nacional de Segurança Pública, Departamento de Pesquisa, Análise da Informação e Treinamento de Pessoal. Relatório Final de Pesquisa: O perfil organizacional das Delegacias Especiais de Atendimento à Mulher. Brasília, 2004.

MUSUMECI, L.; SOARES, B.M. Mulheres policiais: presença feminina na Polícia Militar do Rio de Janeiro. Rio de Janeiro: Civilização Brasileira, 2005.

PONCIONI, P. Tornar-se policial: a construção da identidade profissional do policial no estado do Rio de Janeiro. Tese (Doutorado) -Universidade de São Paulo, São Paulo, 2008.

SCOTT, J. W. A invisibilidade da experiência. Revista do Programa de Estudos Pós-Graduados em História, PUC, Proj. História, São Paulo, n. 16, p. 297-325, fev.1998.

SECRETARIA DE SEGURANÇA PÚBLICA. Disponível em: <http://www.ssp.sp.gov.br>. Acesso em: 11 abr. 2008.

SILVEIRA, M. N. B. As delegadas de polícia de São Paulo: profissão e gênero. Dissertação (Mestrado) - UFSCar, São Carlos, 2009. 


\title{
Police Chiefs: professionalism and gender
}

\begin{abstract}
This work studied the presence of women in the legal profession of police chief, a profession that is "traditionally" masculine. The DDM (Police Stations for Women) was evaluated to verify if the "market reserve" established by this agency has contributed to a process of "subordination" of these professionals front of their peers. The study found that, on the one hand, the inauguration of DDM's channeled more women to work in these agencies, on the other, contributed to an "imprisonment" of their career. This is because, for many delegates, working in a DDM is considered an "obstruction" for this career. The research was conducted in São Paulo, where we studied these Police Districts and Police Stations for Women (DDM's). The study was conducted from 2007 to 2009.
\end{abstract}

Keywords: chief of police; profession; gender; women's police stations; police districts

\section{Las jefas de la policía: profesión y género}

\section{Resumen}

El objetivo central de la investigación fue estudiar la presencia de las mujeres en las carreras de trabajo legal como jefa del distrito de la policía, que es tradicionalmente una profesión masculina. El estudio ha permitido descubrir que, por un lado, la inauguración de la DDM (Delegacias de Defesa da Mulher) canalizados a las mujeres para trabajar en estas comisarías, por otra, han contribuido para una prisión de su carrera. Esto se debe a que, para muchos jefes de la policía, que trabaja en una DDM se considera un obstáculo para la carrera. La investigación se llevó a cabo en São Paulo, donde los distritos de la policía y de la DDM han sido estudiados. Este estudio fue realizado en el periodo de 2007 hasta 2009.

Palabras clave: las jefas de la Policía; género; profesión; Comisaría de la Mujer; Comisaría de Policía.

Data de recebimento do artigo: 28-11-2010

Data de aprovação do artigo: 04-03-2011 